\title{
LAS FORMAS CON ESTRIBILLO EN LA LÍRICA ORAL DEL MEDIOEVO
}

\author{
Vicenç BELTRAN \\ Universitat de Barcelona ${ }^{1}$
}

\begin{abstract}
This essay analyses the musical and stanza forms pertaining to the most archaic poetical categories to be found in the romance languages, in relation to the Medieval oral tradition and to non-cortes literary texts. Recourse to the "zejel", apart from its obvious Arabic origins, can be traced in Provencal to the pre-troubadour period ("Laissatz estar lo gazel"), and the first known instances of "rotrouenge" appeared in the X century in the Alba de Fleury, and the "rondeau", in its simplest form (strophic verses alternating with a refrain), appeared in the works of the writer Hilario el Inglés, a disciple of Abelardo. All the latter refer to hybrid texts, either in Latin (Arabic, where "moaxajas" are concerned) or some early romance tongue or other, which is difficult to identify at times; however, there is no doubt that we can plainly discern the essential traits of what these forms would resemble during the troubadour period and throughout the whole of the Lower Middle Ages.
\end{abstract}

\section{Resum}

En este trabajo se estudian las formas estróficas y musicales de los géneros poéticos más arcaicos en las letras romances, vinculados a la tradición oral del Medioevo y a registros literarios no corteses. El zéjel, además de sus conocidos precedentes árabes, remonta en provenzal al período pretrovadoresco ("Laissatz estar lo gazel"), el ejemplo más antiguo de rotrouenge remonta hasta el siglo X en el Alba de Fleury y el rondeau, en su forma más simple (versos de estrofa que alternan con versos de estribillo) aparece en la obra del escritor Hilario el Inglés, discípulo de Abelardo. En todos estos casos nos hallamos ante textos híbridos, en latín (árabe, en el caso de las moaxajas) y algún romance primitivo, a veces difícil de identificar; sin embargo, en todos estos casos podemos reconocer sin lugar a dudas los aspectos esenciales de cómo serán estas formas en el período trovadoresco y durante toda la Baja Edad Media.

La existencia de una relación más o menos estrecha entre la música y la lírica romance ha sido una constante constatable desde los orígenes de la Musicología y de la Filología, aunque la práctica de ambas disciplinas ha oscilado entre la convicción de dependencias más o menos estrictas, en uno u otro sentido, y la inevitable necesidad de estudiar ambas artes, al menos de facto, con total independencia; sin embargo, durante el período trovadoresco, tanto las teorías entonces vigentes como la naturaleza de los testimonios conocidos obligan a tener en cuenta, de una u otra forma, una relación estricta entre ellas.

1. Este artículo ha sido escrito en el seno del proyecto BFF2000-0759 Poesía y cancioneros. 
Si atendemos a la producción trovadoresca, basta hojear las Vidas de los trovadores, el más antiguo testimonio de crítica literaria aplicada a un texto vulgar, para observar cómo los juicios sobre cada autor unen estrictamente los dos aspectos: de Peire d'Alvernha, por ejemplo, se nos dice que "trobet ben e cantet ben (...) et (...) fez los meillors sons de vers que anc fosson

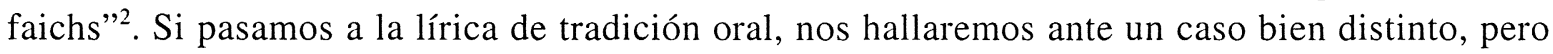
no menos significativo: ausente por lo general de los grandes cancioneros literarios, quizá por ser considerada en el entorno cortés sólo como una subliteratura ${ }^{3}$, sus obras nos han llegado indirectamente, sea mediante citas en textos narrativos (una moda que creó en las primeras décadas del siglo XIII el Roman de Guillaume de Dole de Jean Renart, donde se incorpora el texto con sus melodías $)^{4}$, sea a partir de cancioneros musicales, como suele suceder con los motetes franceses ${ }^{5}$ o con los textos del Ars nova italiana ${ }^{6}$. La dimensión musical resulta intrínseca a este registro poético, y es a menudo éste el factor que nos ha permitido la conservación de unas obras que no interesaban, por lo general, a los compiladores de los cancioneros líricos.

Estas variedades poéticas, estudiadas antaño hasta la saciedad por haber sido involucradas en la discusión sobre los orígenes de la lírica romance ${ }^{7}$, se encuentran hoy aquejadas de dos problemas fundamentales desde la perspectiva filológica: por una parte, la caída en desuso de aquel tipo de trabajos ha hecho que sean a veces dejadas de lado en el ámbito de la Filología románica $^{8}$, aunque en los últimos años ha reverdecido el interés de los estudiosos; por otra parte,

2. J. Boutière y A.-H. Schutz, Biographies des troubadours. Textes provençaux des XIII et XIVI siècles, Bibliothèque Méridionale, xxvii, Toulouse-Paris, Privat-Didier, 1950, reimpresión facsimilar de New York-London, Johnson Reprints Corporation, 1971 , p. 218; puede verse también la versión al castellano de M. de Riquer, Vidas y retratos de trovadores. Textos y miniaturas del siglo XIII, Barcelona, Círculo de lectores, 1995, p. 139.

3. Véase al respecto mi "Poesía popular ¿cultura cortés?", Romance Philology, 55, 2001, pp. 21-68.

4. Para este aspecto véase Meritxell Simó, La arquitectura del 'roman courtois' en verso con inserciones líricas, Bern, Peter Lang, 1999, donde puede encontrarse toda la tradición filológica sobre el caso.

5. Gaston Raynaud, Recueil de motets français des XIIe et XIIIe siècles publiés d'après les mss., avec introduction, notes, variantes et glossaires. Suivis d'une étude sur la musique au siècle de Saint Louis, par Henri Lavoix fils, , 2 vol., Paris, P. Wieg, Libraire-Editeur, 1881-1883, que cito por la reimpresión facsimilar de Genève, Slatkine Reprints, 1974.

6. Giuseppe Corsi, Poesie musicali del Trecento, Bolonia, Commissione per i Testi di Lingua, 1970.

7. No es este el momento oportuno para reconstruir la trayectoria de estos estudios; quien lo desee puede ver mi “Poesía popular antigua, ¿cultura cortés?”, arriba citada, donde di las referencias imprescindibles. Para el objetivo que aquí pretendo baste Margit Frenk, La lírica pretrovadoresca, en Grundriss der romanische Literaturen des Mittelalters, vol. II, Les genres lyriques, fasc. 2, Heidelberg, Carl Winter-Universitätverlag, 1979, pp. 5-79 y mejor aún su versión más desarrollada, Las jarchas mozárabes y los comienzos de la lírica románica, México, El Colegio de México, 1975, que cito por la reimpresión de 1985, pp. 21-43

8. A decir verdad, en el ámbito de la hispanística, la fidelidad a la escuela de Ramón Menéndez Pidal ha hecho que éste sea un tema prioritario de trabajo, como revela en particular la obra de Margit Frenk y, muy especialmente, su Corpus de la antigua lírica popular hispánica (siglos XV al XVII), Madrid, Castalia, 1987 y su Corpus de la antigua lírica popular hispánica. Suplemento, Madrid, Castalia, 1992. Muy al contrario, en la Filología francesa el tema fue casi abandonado desde comienzos del siglo XX hasta la aparición de los trabajos de Pierre Bec, en especial su La lyrique française au Moyen-Age (XII-XIII siècles). Contribution à une typologie des genres poétiques médiévaux, Paris, A \& Picard, 1977; antes y después de esta publicación, las escasas investigaciones sobre el tema han tenido un carácter marcadamente descriptivo o se han limitado a la edición estrictamente filológica de los textos como es el caso de Nico H.J. Van den Boogaard, Rondeaux et refrains. $D u X I I^{e}$ siècle au début du XIV", Paris, Kincksieck, 1969. En el ámbito italiano, este tipo de trabajos son prioritariamente ocupación de musicólogos (véase por ejemplo Nino Pirrotta, Il Codice Rossi 215. The Rossi Codex 215, Studio introduttorio ed edizione in facsimile / Introductory Study and Facsimile Edition, Ars Nova, 2,Lucca, Libreria Musicale Italiana Editrice, 1992) o de la cultura popular (Giovanni B. Bronzini, Filia, visne nubere? Un tema di poesia popolare, Roma, Edizioni dell'Ateneo, 1967), y sólo de vez en cuando atraen la atención de los filólogos (como Giuseppe Tavani, "Le "poesie per musica del codice Squarcialupi', en sus Restauri testuali, Roma, Bagatto Libri, 2001, pp. 199-220). 
al centrarse en la problemática de su origen popular o letrado, y al imponerse la necesidad de clasificar y filiar cada uno de los escasos especímenes primitivos conocidos, no siempre fueron definidos con precisión sus aspectos morfológicos, y la terminología, los criterios clasificatorios y la adscripción de los testimonios conservados a una u otra categoría varían considerablemente según los estudiosos. Creo por tanto que, en reconocimiento a la labor musicológica desarrollada por el admirado y estimado Josep Pavia i Simó, quizá no será ocioso que un filólogo ofrezca un estado de la cuestión y una taxonomía de las formas de poesía oral con estribillo en la primitiva lírica romance a la altura de nuestro tiempo.

El aspecto más sobresaliente de las formas poéticas de tradición oral es en primer lugar la simplicidad; se trata de estrofas construidas por lo general sobre una sola rima, que contrasta con la del estribillo, también, por lo general, monorrimo. Por otra parte, además de la extrema simplicidad de estas formas, de pocos versos de extensión y de no más de dos o tres rimas por estrofa, faltan también las exquisiteces en la construcción del estrofismo, los recursos de enriquecimiento de la rima y cualquier otra manifestación de refinamiento formal. Sus formas musicales son también muy sencillas, organizadas sobre una sola frase que se va repitiendo para cada nuevo verso, con otra frase distinta que cubre cada uno de los versos del estribillo. Más adelante daremos algunas muestras, basadas en los trabajos de reputados musicólogos; pero por el momento creo que bastan estos apuntes que, evidentemente, contrastan con la extraordinaria complejidad estrófica y musical de la canción trovadoresca, tan bien estudiada por Dante Alighieri ${ }^{9}$.

La más sencilla de las formas con estribillo es la que podemos llamar genéricamente rotrouenge a partir del género francés que la usó en el ámbito trovadoresco ${ }^{10}$, pero no le es en absoluto privativa. Consta de una estrofa monorrima que se acompaña de un estribillo también monorrimo, una melodía de sólo una frase para la estrofa, otra, también de una sola frase, para el estribillo:

$$
\alpha \quad \alpha / \beta
$$

\author{
10a 10a 10a 10a / 6B $10 \mathrm{~B}^{11}$
}

9. Véase por ejemplo la Edición, traducción, introducción y notas de Manuel Gil Esteve y Matilde Rovira Soler de su De vulgari eloquentia, Madrid, Palas Atenea, 1997, especialmente el libro segundo; estos datos fueron aplicados a la poesía trovadoresca por Roger Dragonetti, La technique poétique des trouvères dans la chanson courtoise. Contribution à l'étude de la rhétorique médiévale, Genève, Slatkine, 1979, pp. 381-385 y Jean Maillard, Adam de la Halle. Perspective musicale, Paris, Champion, 1982.

10. Para la rotrouenge francesa véase Friedrich Gennrich, Die altfranzösische Rotrouenge, Halle, 1925, Jean Beck, La musique des troubadours, Paris, Henri Laurens, 1928, pp. 100-104, Paul Verrier, Le vers français, París, 1931, vol. I, pp. 174-179 y 204-212 (aunque no sea siempre fácil distinguir entre su riquísima información y sus complejas conjeturas), Luciano Formisano, Gontier de Soignies. Il canzoniere, Milano-Napoli, Riccardo Ricciardi, 1980, y Bec, en especial su La lyrique française au Moyen-Age (XII-XIII siècles), pp. 183-189, para la provenzal, Marie-Odile Sánchez-Macagno, Retroencha. Coblas retronchadas: contribution à un étude, col. Tesis doctorals microfitxades, Barcelona, Universitat, 1989, tesis de doctorado bajo mi dirección.

11. Gennrich, $O b$. cit., pp. 22-23. Corresponde a la chanson de toile En un vergier, lez une fontenele, cuyo texto puede verse también en mi Ki s'antraimment soweif dorment'. 20 chansons de toile, Barcelona, PPU, $1986, \mathrm{n}^{\circ} 9$. 
El ejemplo que he reproducido corresponde a una chanson de toile, género de contenido amoroso y de estructura narrativa, quizá el más sencillo de los representantes de esta tipología estrófica. Corresponde plenamente con el corpus más simple de la cantiga de amigo galaico-portuguesa, construida normalmente sobre un dístico con estribillo, a veces de estrofismo un tanto más amplio; el ejemplo más arquetípico lo podemos encontrar en la obra de Martin Codax, que, a su vez, tiene la enorme ventaja de ser la única que nos ha llegado con melodías:

$$
\begin{array}{lc}
\alpha & \alpha^{\prime} \quad \beta \\
9 \mathrm{a} & 9 \mathrm{a} / 5 \mathrm{~B}^{12}
\end{array}
$$

Se trata, por otra parte, de una de las formas poéticas más arcaicas que conocemos, documentada ya, al menos en sus rasgos aparentemente fundamentales, en el texto enigmático que conocemos como Alba de Fleury:

Phebi claro nondum orto iubare, fert Aurora lumen terris tenue:

spiculator pigris clamat: 'Surgite

L'alba par umet mar atra sol

Poy pas abigil miraclar tenebras ${ }^{13}$

Todo son problemas en este enigmático poema, desde el sentido del estribillo hasta su interpretación. Pero a pesar alguna anomalía (las dos rimas del estribillo, la rima a la latina, con repetición de sólo la vocal final en la estrofa), no parece aventurado juzgar este texto de tres estrofas, probablemente del siglo X, como el testimonio más antiguo conservado de la forma poética que denominamos rotruenge, y que no carece de representación en la lírica mediolatina ${ }^{14}$, ni de ejemplos romances o latino-romances muy característicos en el Sponsus, un tanto posterior:

12. Corresponde a la cantiga $\mathrm{n}^{\circ} 1$ de este trovador, Ondas do mar de Vigo. Véase el estudio en Higini Anglès, La música de las cantigas de Santa María del rey Alfonso X el Sabio, vol. III, 2, Las melodías hispanas y la monodía lírica europea de los siglos XII-XIII, Barcelona, Biblioteca Central, 1958, pp. 447-453, transcripciones en las pp. 53-55 de la parte musical. Véase también el trabajo más reciente de Manuel Pedro Ferreira, O som de Martin Codax. Sobre a dimensão musical da lírica galego-portuguesa (séculos XII-XIV), Lisboa, Imprensa Nacional-Casa da Moeda, 1986. La edición literaria más solvente es con mucho la de Celso Ferreira da Cunha, O cancioneiro de Martin Codax, Rio de Janeiro, 1956, del que hay reimpresión facsimilar en su Cancioneiros dos trovadores do mar, edição preparada por Elsa Gonçalves, Lisboa, Imprensa Nacional-Casa da Moeda, 1999.

13. Cito, por comodidad de lectura, según la edición interpretativa de Alfred Jeanroy, Les origines de la poésie lyrique en France au Moyen Age, Paris, cuarta edición, París, Champion, 1969 (primera de 1889), p. 73. Otra edición muy cuidada puede verse en Ruggiero M. Ruggieri, Testi antichi romanzi, Modena, 1949, vol. II, $\mathrm{n}^{\circ}$ 16, y una transcripción paleográfica en el Inventaire systématique des premiers documents des langues romanes, édité par Barbara Frank et Jörg Hartmann avec la coordination de Heike Kürschner, Tübingen, Gunter Narr Verlag, 1997, vol. II p. 219 (\$2058), donde se encontrará también la referencia a las ediciones y los estudios más significativos (para otros aspectos véase lo que dice en el vol. I, pp. 21 y 95-96). Para un estado de la cuestión desde el punto de vista literario, véase Maria Luisa Meneghetti, Le origini, en Storia delle letterature medievali romanze, Roma-Bari, Laterza, 1997, pp. 169-177.

14. Ya señaló algunos casos Hans Spanke, "Die Metrik der Cantigas", en H. Anglès, La música de las cantigas..., vol. III, 1, pp. 193-198. He de señalar que también se ajusta a esta forma parte del texto provenzal y parte del texto latino con estribillo romance en el Sponsus. Dramma delle vergini prudenti e delle vergini stolte, testo letterario a cura di d'Arco Silvio Avalle, testo musicale a cura di Rafaello Monterosso, Col. Documenti de Filologia, 9, Milano-Napoli, Riccardo Ricciardi, 1965 (véase el estado de la cuestión sobre este interesantísimo texto en Maria Luisa Meneghetti, Ob. cit., pp. 185-189). 
Oiet, virgines, aiso que vos dirum!

Eiset presen que vos comandarum!

Atendet un espos, Jesu'salvaire a nom.

Gaire no i dormet $^{15}$.

Sigue un largo fragmento en latín con estribillo romance, de idéntica estructura:

Nos virgines que ad vos venimus,

negligenter oleum fudimus;

ad vos orare, sorores, cupimus,

ut et illas quibus nos credimus.

Dolentas, chaitivas, trop $i$ avem dormit! ${ }^{16}$.

Por su parte, la melodía, puede definirse en ambos casos según el modelo arriba descrito, con la excepción de substituir el último verso de la estrofa por un recitativo ${ }^{17}$.

Ni qué decir tiene que el uso que aquí hago del término rotrouenge es traslaticio, y no hace referencia al género lírico, que nos ha llegado sólo a través de adaptaciones corteses generalmente más elaboradas; en esto sigo las huellas de Gennrich, el estudioso del que parten todos estos trabajos. Las adaptaciones trovadorescas de los géneros líricos adoptan esquemas estróficos y musicales más complejos, generalmente desdoblando cada miembro de la estrofa en dos versos de rimas alternas; el esquema melódico suele complicarse también con la introducción de más frases, quizá con frases nuevas en cada verso de alguna de sus secciones, según el esquema de la canción cortés. Otras veces, encontramos contaminaciones con esquemas procedentes de otros géneros, y unos u otros fenómenos pueden alterar la forma estrófica, la musical o las dos. La casuística puede ser, por tanto, complejísima; pero a mi parecer lo más importante es fijar el modelo básico, que se ajustaría a lo aquí expuesto.

A este esquema le corresponden algunas características subsidiarias, pero no menos significativas. Por ejemplo, la extensión de estribillo y estrofa debe seguir un par de reglas muy sencillas: los versos del estribillo no son más largos que los de la estrofa (serán, en el mejor de los casos, del mismo número de sílabas) y el número de versos del estribillo tampoco será superior al de la estrofa; preferentemente es más breve, en el mejor de los casos, alcanza su misma longitud. Por otra parte, tanto en las cantigas de amigo como en las rotrouenges hay una intensa relación semántica entre estribillo y estrofa, a menudo íntimamente encabalgados:

Fui eu, madre, lavar meus cabelos

a la fonte e paguei-m'eu d'elos

$$
\text { e de } m i \text {, louçãa } a^{18}
$$

15. Sponsus, p. 72.

16. Ibidem, p. 74.

17. La edición musical cierra el volumen en las últimas páginas, sin numeración.

18. Cito por mi Canción de mujer, cantiga de amigo, Barcelona, PPU, 1987, $\mathrm{n}^{\circ}$ 6, de Johan Soarez Coelho. 
Bele Yolanz en chambre koie sor ses genouz pailes desploie: cost un fil d'or, l'autre de soie. Sa male mere la chastoie:

- Chastoi vos en, bele Yolanz'.

Esta relación no siempre queda de manifiesto en las ediciones; en la poesía letrada o literaria, desde los mismos trovadores, el estribillo es sintácticamente autónomo, y carece de relación textual explícita con el texto de la estrofa. Por otra parte, la sintaxis de este tipo de obras es a menudo muy laxa, basada en coordinaciones que no siempre tienen valor sintáctico estricto, o en yuxtaposiciones cuya interpretación semántica puede variar de una estrofa a otra, de ahí que en las ediciones tienda a darse autonomía a ambas partes mediante la interposición de un punto que, por estas razones, no siempre dificulta la lectura. Sin embargo, también en este género es necesario partir de la interdependencia entre ambas partes, que tan visible resulta, por ejemplo, en el rondeau.

No olvidemos, por otra parte, que el desarrollo narrativo de estos poemas crea otro tipo de dificultades. En otra chanson de toile, Belle Yzabel ${ }^{20}$, la protagonista ha sido entregada en matrimonio a un villano, fuera de su tierra, como castigo por tener un enamorado; de ahí el estribillo:

\section{E amins!}

Por medissans seus fors de mon païs

Entonces su criada le ofrece, y ella acepta, un cortois chevalier que alegre sus días; el estribillo, mecánicamente repetido, carece ya de sentido en este contexto. Sucede exactamente lo mismo en una preciosa cantiga de Nuno Fernandez Torneol; al principio, el estribillo encaja muy bien con un entorno paradisíaco:

Levad', amigo que dormides as manhanas frias;

todalas aves do mundo d'amor dizian

Leda mh and' $e u^{21}$

pero al final, destruida la armonía de este amor y sus atributos, el estribillo se repite sin variación y, por tanto, en frontal desajuste con el contenido narrativo de estas estrofas:

Vós lhi tolhestes os ramus en que pousavan

e lhis secastes as fontes hu sse banhavan.

Leda mh and'eu.

19. Cito por mi Ki s'antraimment soweif dorment, $\mathrm{n}^{\circ}$ 12, anónima.

20. Cito por mi edición, $n^{\circ} 13$.

21. Cito otra vez por mi Canción de mujer, cantiga de amigo, n 3. Véase mi estudio de esta composición, donde analizo algunos de estos problemas: "Nuno Fernandez Torneol y el simbolismo de la canción de mujer", en Amor, escarnho y linaje en la literatura gallego-portuguesa, Bilbao, Universidad, 2002, pp. 47-74. 
De ahí que algunos poetas utilizaran un doble estribillo, cambiado a tenor del desarrollo argumental; en otra chanson de toile, las premoniciones por la suerte del enamorado se acompañan del estribillo $E$ or en ai dol; tras conocerse su muerte en una justa, se metamorfosea en $E$ or en ai dol / por vos devenrai nonne en l'eglyse saint Pol ${ }^{22}$. Otro caso aún más sutil, esta vez en la pluma de Pero Meogo: una joven vuelve tarde de la fuente, donde se había demorado con su amigo, y recibe la reprimenda de su madre, a la que intenta engañar:

Tardei, mia madre, na fría fontana, cervos do monte volvían a augua.

$$
\text { Os amores } e i^{23} \text {. }
$$

El pretexto funciona distintamente en los dos niveles de la cantiga, el referencial y el simbólico. Si la joven acudió a la fuente a lavar o a por agua, es obvio que hubo de esperar a que aclarara; pero el sentido profundo sabemos cuál es, y explicitarlo es función del estribillo, que sigue repitiéndose cuando la madre replica con otro argumento de sentido común:

\author{
-Mentís, mia filha, mentís por amigo, \\ nunca vi cervo que volvess'o río. \\ Os amores ei.
}

He de subrayar que la historia de esta forma no queda reducida al francés ni al galaicoportugués ${ }^{24}$, ni tampoco al siglo XIII, aunque es seguramente en este período cuando alcanza su máximo desarrollo. En los textos popularizantes del cuatrocientos podemos encontrarlo alguna vez, sobre todo en francés ${ }^{25} \mathrm{y}$, aunque residualmente, también en la canción tradicional castella$\mathrm{na}^{26}$. Nos hallamos sin embargo ante técnicas formalmente muy simples, seguramente, también, muy primitivas, pero usadas con sabiduría y eficacia por los poetas que las adoptaron en las cortes feudales duecentistas y trecentistas. Tampoco cabe ninguna duda de que estamos ante los productos de la poética medieval más afines a nuestras posiciones estéticas, de modo que hoy los podemos degustar sin casi mediación cultural alguna, más allá de las dificultades, casi nunca considerables, de su veste lingüística. Un universo poético, ideológico, técnica y estéticamente ajeno

22. Ki s'antraimment soweif dorment, $\mathrm{n}^{\circ} 10$.

23. Canción de mujer, cantiga de amigo, $\mathrm{n}^{\circ}$ 37. Para la funcionalidad de este estribillo véase el análisis de $\mathrm{R}$. Senabre, "Las cantigas de Pero Meõgo", en Anuario de Estudios Filológicos, 3, 1980, pp. 281-287.

24. Véase por ejemplo la viadeira de Cerverí de Girona que puede verse en la edición de Martín de Riquer, Obras completas del trovador Cerveri de Girona, Barcelona, Instituto de Estudios Mediterráneos, 1947, $n^{\circ} 1$. Otros textos de la misma tradición provenzal y catalana han sido recogidos por José Romeu Figueres, "El cantar paralelístico en Cataluña. Sus relaciones con el de Galicia y Portugal y el de Castilla", Anuario Musical, 9, (1954), pp. 3-55

25. Théodore Gérold, Chansons populaires des XVe et XVIe siècles avec ses mélodies, Strasbourg, 1913, reimpresión facsimilar, Genève, Slatkine, $1976, \mathrm{n}^{\circ} 7$ por ejemplo. Véase para esta forma lo que dice en las pp. xxxvi y xxxvii de la introducción.

26. Antonio Sánchez Romeralo, El villancico, Biblioteca Románica Hispánica. Estudios y Ensayos, 131, Madrid, Gredos, 1969, pp. 334-336 y Fernando Baños Vallejo, "La más antigua lírica popular castellana: otra tipología", en Archivum, 41-42, 1991-1992, pp. 33-64, especialmente pp. 53-54. 
al mundo de los trovadores. Sin embargo, el destino de la rotrouenge fue menguado: a diferencia de las formas primitivas que estudiaremos a continuación no consiguió consolidarse en el período postrovadoresco, cuando el eje de la lírica empezó a girar en torno a las formas fijas.

Si la rotrouenge es una forma fija panrománica, el rondeau ${ }^{27}$ fue originariamente una invención de escasa difusión fuera del territorio de la Francia actual, que acabó integrándose en el repertorio de los géneros corteses a partir del tercer cuarto del siglo XIII, en la obra de Adam de la Halle ${ }^{28}$; en general apenas se extendió fuera de su país de origen hasta el punto de afirmar el tratadista Gidino de Sommacampagna que "li rotondelli molto sono usitati in Franza"29; otro tanto le sucedió al compilador de las Leys d'amors, para quien "Alcu commenso far redondels en nostra lenga losquals hom solia far en lengatge frances" ${ }^{30}$. Su forma canónica difiere según la lengua; en francés, de donde toma el nombre, sigue un esquema originalmente muy sencillo, aunque fue progresivamente complicado después de su adopción por la poesía cortesana, en particular tras Charles d'Orléans ${ }^{31}$ :

$$
\begin{aligned}
& \alpha \beta / \alpha \alpha \alpha \beta / \alpha \beta \\
& \mathrm{AB} / \mathrm{aAab} / \mathrm{AB}^{32}
\end{aligned}
$$

27. Véase Gaston Raynaud, Rondeaux at autres poésies du $X V^{e}$ siècle, Société des Anciens Textes Français, 30, Paris, 1889, pp. xxxv-lii, reimpresión facsimilar de New York-London Johnson Reprint, 1968, Henri Chatelain, Recherches sur le vers français au $X V^{e}$ siècle, Paris, 1907, reimpresión facsimilar, Genève, Slatkine Reprints, 1974, pp. 199-221, Jeanroy, Les origines de la poésie lyrique au Moyen Âge, pp. 406-425, P. Verrier, Ob. cit., vol. I pp. 227-243 y George Lote, Histoire du vers français, Paris, Éditions Boivin et C ${ }^{\text {ie }}$., 1951, vol. II, pp. 235-238, así como Gilbert Reaney, "Concerning the origins of the Rondeau, Virelai and Ballade forms", en Musica Disciplina, 6, 1952, pp. 155-166, que resume las diversas teorías; para el aspecto musical, véase el estado de la cuestión, todavía útil en cuanto a las aportaciones antiguas, de Higini Anglès, El còdex musical de las Huelgas. Música a veus dels segles XIII-XIV. Introducció, facsímil i transcripció, Barcelona, Institut d'Estudis Catalans, 1931, p. 54 y su La música a Catalunya fins al segle XIII, Barcelona, Institut d'Estudis Catalans,1935, pp. 342-343. El corpus francés medieval completo puede verse en Friedrich Gennrich, Rondeaux, Virelais und Balladen, Desden-Göttingen, 1921-1927 y en la edición del texto más cuidada filológicamente de N. Van den Boogaard citada en la nota 8.

28. Aparte de la edición clásica de [Charles] E[dmond-Henry] de Coussemaker, Oeuvres complètes (poésies et musique), Paris, 1872, hoy en reimpresión facsimilar de Genève, Slatkine Reprints, 1982, existen diversas ediciones de este poeta y, en particular, de este género poético, la más reciente la de D. Hubbard Nelson y H. van der Werf, The Lyrics and Melodies of Adam de la Halle, Lyrics Edited and Translated by Deborah Hubbard Nelson. Melodies Edited by Hendrik van der Werf, New Yok-London, Garland Publishing, 1985, así como una amplia selección en S. Rosenberg y H. Tischler, Chanter m'estuet. Songs of the Trouvères, Bloomington, Indiana University Press, 1981 y un estado de la cuestión también muy reciente en el artículo correspondiente de R. Bossuat, L. Pichard, G. Raynaud de Lage, G. Hasenohr y M. Zink, Dictionnaire des lettres françaises. Le Moye Age, Paris, Fayard, 1994. Para el papel de Adam de la Halle en el desarrollo musical del medioevo, pero sobre todo para sus rondeaux, véase J. Maillard Adam de la Halle: perspective musicale, Paris, Honoré Champion, 1982. Además de las ediciones de poesía popularizante de origen francés que he ido citando y de otras que seguirán, véase la antología muy completa de Karl Bartsch, Altfranzösische romanzen und pastourellen, Leipzig, Vogel, 1870, reimpresión facsimilar, Ginebra, Slatkine, 1973.

29. Citado por Pierre Bec, Ob. cit., 1977, vol. I, p. 225. Sin embargo el género aparece también definido en la fuente de todos los tratadistas italianos de formas poéticas, Antonio da Tempo, Delle rime volgari, ed. Giusto Grion, Bologna, 1869, ristampa anastatica, Bologna, Forni Editore, 1970, especialmente pp. 134-139 y en su versión latina, Summa Artis Rithimici Vulgaris Dictaminis, edizione critica a cura di Richard Andrews, Bologna, Commissione per i Testi di Lingua, 1977, pp. 66-70.

30. Guilhem Molinier, Leys d'amors, edición de J. Anglade, 4 vol., Toulouse, 1919-1920, reimpresión anastática de Johson Reprint Corporation, New York-London, 1971, vol. II p. 185.

31. Este es un período que aquí no me interesa y para el que se puede partir del trabajo de Daniel Poirion, Le poète et le Prince, París, Presses Universitaires de France, 1965, pp. 311-360.

32. Tomo el esquema de Bec, La lyrique française au Moyen Âge, vol. I, p. 226. Para el origen del género véase lo dicho en la nota 27. 
Este sería por ejemplo el esquema estrófico y musical de un rondeau de Adam de la Halle:

Li dous regars de ma dame

me fait esperer merchi.

Diex gart son gent cors de blame!

Li dous regars de ma dame.

Je ne vi onques par m'ame

dame plus plaisant de li:

Li dous regars de ma dame

me fait esperer merchi ${ }^{33}$

Si comparamos este esquema con el de la rotrouenge, las diferencias saltan a la vista. En primer lugar, el estribillo es a la vez inicial y final, pero su primer verso se inserta también en el seno de la estrofa; por otra parte, el poema ya no se divide en dos partes, estrofa y estribillo, diferenciadas por la melodía y las rimas, sino que ambas, además de confundirse por la inserción del uno en la otra, comparten las mismas rimas y las mismas frases melódicas. A veces se ha querido filiar el rondeau y la rotrouenge mediante un sencillo esquema de derivación, por inserción del estribillo, o por combinación de más o menos rimas; creo sin embargo que corresponden a esquemas estructurales enteramente distintos, cuando no diametralmente opuestos. Lo que sí resulta común a ambos géneros es la íntima asociación entre estribillo y estrofa.

El provenzal conoció una forma emparentada, la balada; fundamentalmente, la diferencia esencial se da en la existencia de una doble inserción del primer verso del estribillo, que enriquece y amplifica la estructura estrófica:
Mort m'an li semblan que ma dona'm fai
e li seu bel oil amoros e gai.
Qu'eu non trob conseil, s'eu de li non l'ai
Mort m'an li semblan que ma dona'm fai
per qu'eu joinchas mas denant li venrai,
Mort m'an li semblan que ma dona'm fai
preiant humilment, quant far o poirai,
que $\mathrm{m}$ facha socors, sevals d'un dolz bai ${ }^{34}$.

No es la única forma presente en provenzal, donde el corpus es muy escaso (cinco textos) y rico en variantes como sólo encontramos en francés en los testimonios más antiguos. Veamos por ejemplo una de las dos baladas de Cerverí de Girona:

33. Texto en Boogaard, Ob. cit., n 71 y musical en Maillard, Ob. cit., p. 122.

34. Karl Bartsch, Chrestomathie Provençale (Xe-XVe siécles), entiérement refondue par Eduard Koschwitz, Marburg, N. G. Elwert, 1904, reimpresión facsimilar de Hildesheim-New Yord, Georg Olms Verlag, 1971, col. 267. 


\begin{abstract}
A la plug'e al ven iran
çels que muyllers an,

çels que muyllers an.

L'amic iran espigan,

a la plug'e al ven iran,

e cil que no spigaran

a la plug'e al ven iran

las domnas seran a lor dan,

e-ls escarniarn,

e.ls escarniran ${ }^{35}$
\end{abstract}

Como vemos, se aparta del rondeau primitivo en que el estribillo es monorrimo, lo que produce una estrofa también monorrima; otras veces, estribillo y estrofa contienen rimas distintas $^{36}$, o la rima de la estrofa es independiente de la o las del estribillo ${ }^{37}$ aunque en los rondeaux más arcaizantes y antiguos, estas anomalías no son nada $\operatorname{raras}^{38}$. Sin embargo, en provenzal encontramos un segundo tipo de balada que parece haber sido una invención de Cerverí de Girona, y en la que el estribillo no inserta dos veces su primer verso, sino los dos primeros en su mismo orden:

Si voletz que $\cdot$ m laix d'amar, ço [dic] que far no.s poria, laxatz a ten gen parlar, bela douza dona mia.

E laxatz lo douz esgar, si voletz que'm laix d'amar, e vostra gran cortesia ço [dic] que far no.s poria, e.l vostre gen domneyar; c'ab vostr'avinen paria faitz la gent enamorar; doncs, cossi-us dezamaria? Si voletz... ${ }^{39}$

35. Cerverí de Girona, Ed. cit., n ${ }^{\circ}$ 3. Pueden verse otros ejemplos en M. de Riquer, Los trovadores, Barcelona, Planeta, 1975, vol. I, p. 46 (con una definición de género) y $n^{\circ} 363$ (una de las reproducidas en la página citada). La lista completa figura en Istvan Frank, Répertoire métrique de la poésie des toubadours, Paris, Champion, 1966, p. 70; sin embargo, dos no son propiamente baladas por las razones que expuse en mi "La balada provenzal en la poesía gallego-portuguesa", en La lengua y la literatura en tiempos de Alfonso X, Murcia, Universidad, 1985, pp. 79-90, pp. 79 y 80 y notas.

36. Es el caso de las baladas Coindeta sui (texto en Carl Appel, Provenzalische Chrestomathie mit Abriss der Formenlehre und Glossar, Leipzig, Reisland, 1930, reimpresión facsimilar Hildesheim-New York, Georg Olms Verlag, 1971, ${ }^{\circ}$ 47 -el número 48 debe ser rechazado de este género por no tener realmente estribillo, reducido a una sola palabra que se repite mecánicamente tras cada verso-, así como Bartsch, Provenzalische Crestomathie, col. 269).

37. Karl Bartsch, Chrestomathie Provençale, col. 268, D'amor m'estera y C. Appel, Provenzalische Crestomathie, $\mathrm{n}^{\circ} 45$, Quant lo gilos er fora.

38. Véase por ejemplo Nico H.J. Van den Boogaard, Rondeaux et refrains. Du XII siècle au début du XIV"e, $\mathrm{n}^{\circ} 22-$ 24 , monorrimos, o el $\mathrm{n}^{\circ} 12$ y 35 , con rimas distintas para estribillo y estrofa.

39. Ed. M. de Riquer, $n^{\circ} 4$. 
Para entender cabalmente la variedad y riqueza de las combinaciones provenzales, y no sólo las provenzales, hemos de acudir a la lírica latina, en la que encontramos todas estas variedades y algunas más ya señaladas por Hans Spanke ${ }^{40}$. Allí hallaremos inserciones del estribillo en la estrofa, con o sin rima, pero generalmente más próximos al modelo de inserción del rondeau que al de la balada; no sucede lo mismo si nos remontamos a un autor más antiguo, de mediados del siglo XII, Hilario el Inglés, discípulo de Abelardo que, junto a otras formas, algunas de ellas muy próximas a la rotrouenge, parece ejemplificar la configuración más antigua y a la vez la más primitiva de estribillo insertado:

Nisi visus fallitur,

Jo en ai.

Tesaurus hi cernitur,

De si grant merveile en $a i^{41}$.

Si aceptamos que las distintas variedades de este tipo poético parten de esta forma, y no de las más complejas y desarrolladas del rondeau y la balada, adquieren sentido una serie de creaciones presentes en otros ámbitos de las letras romances. Me refiero, por ejemplo, a este ejemplo un tanto tardío, del rey don Denis de Portugal, nacido en 1261:

Amad'e meu amigo, valha Deus!

vede la frol do pinho

e guisade d'andar ${ }^{42}$.

En la lírica galaico-portuguesa, distintas variedades del tipo de esta cantiga conviven con otras que parecen inspirarse en las canónicas del rondeau y la balada, tomadas sin lugar a dudas directamente de modelos franceses y provenzales cuya adaptación resulta fácil seguir y datar ${ }^{43}$. También las encontramos en la lírica tradicional castellana del primer Renacimiento, aunque, como sucede en este período, con estribillo antepuesto, y con la particularidad de presentar los versos insertados en las posiciones pares de las estrofas, que podemos relacionar con técnicas específicas del virelai:

40. "Die Metrik der Cantigas", en H. Anglès, La música de las cantigas..., vol. III,1, pp. 202-207 y 218-225.

41. Hilarri versus et ludi, ed. Jacques-Joseph Champollion Figeac, Hilarii versus et ludi, London-Paris, 1835, pp. 37-38. Sigue otra pieza con la misma estructura. Sobre este autor, poco estudiado, véase Peter Dronke, Medieval Latin and the Rise of European Love-Lyric, Oxford, Clarendon, 1968, reimpresión de 1999, pp. 217-220 y el estado de la cuestión de Luis Astey V., Los tres dramas de Hilario y otros tres dramas temáticamente afines, México, Universidad Nacional Autónoma de México, 1995.

42. Tomo el texto de José Joaquim Nunes, Cantigas d'amigo dos trovadores galego-portugueses. Edição crítica, acompanhada de introdução, comentário, variantes e glossário, Coimbra, Universidade, 1926-1928, reimpresión facsimilar, New York, Kraus Reprint, 1971 y Lisboa, Centro do Livro Brasileiro, 1973, vol. 2, n 21 (también en la edición crítica de Henry Roseman Lang, Das Liederbuch des König Denis von Portugal, Halle, Max Niemeyer, 1894, Hildesheim-New York, Georg Olms Verlag, 1972, $n^{\circ}$ 94).

43. Véase mi "Rondel y refram intercalar en la lírica gallego-portuguesa", en Studi Mediolatini e Volgari, 30, 1984, pp. 69-89 y mi "La balada provenzal en la poesía gallego-portuguesa", en La lengua y la literatura en tiempos de Alfonso X, arriba citado. 
No tengo cabellos, madre,

mas tengo bonico donayre.

No tengo cabellos, madre, que me lleguen a la cinta, mas tengo bonico donayre con que mato a quien me mira. Mato a quien me mira, madre, con mi bonico donayre ${ }^{44}$.

Por fin, si atendemos ahora a otros ámbitos literarios, veremos alguna variedad de inserción menos significativa, pero al parecer directamente enlazada con ésta; me refiero a glosas que empiezan repitiendo el incipit del estribillo como esta:

\author{
Fort'é la straniança \\ laond'eo son in gran penseri, \\ però ch'eo sono strayneri \\ vivo in gran disiança. \\ Fort'é la straniança \\ laond'eo son in gran penseri, \\ chome bon chavaleri \\ meno çoiosa vita, \\ ma io sto'n desiança \\ de retornare a Teri $(\ldots)^{45}$
}

En estos casos no suele haber más inserciones, ni en el seno de la estrofa, ni en las estrofas sucesivas, puesto que nos hallamos por lo general ante poemas del tipo virelai con sus tres glosas; encuentro también ejemplos en francés ${ }^{46}$, pero lo curioso de esta modalidad de inserción es que tales engarces desaparecen (o, en el mejor de los casos, son reducidos a palabras sueltas) en los autores que adaptaron estos esquemas a las formas fijas que habían de dominar el panorama de la gran poesía lírica durante los siglos XIV y XV, tanto en Dante o Cavalcanti como en Machaut, por no citar sino nombres de primerísima fila ${ }^{47}$.

44. Margit Frenk, Corpus de la antigua lírica popular hispánica (siglos XV al XVII), Madrid, Castalia, 1987, $\mathrm{n}^{\circ}$ 124. Esta autora estudió esta forma de la lírica tradicional castellana en su "Glosas de tipo popular en la antigua lírica", Nueva Revista de Filología Hispánica, 12, 1958, pp. 301-334, luego reimpreso en sus Estudios sobre lírica antigua, Madrid, Castalia, 1978, pp. 267-308, especialmente pp. 275-281.

45. Tomo el texto de Adriana Caboni, Antiche rime italiane tratte dai Memoriali bolognesi, Testi e manuali, 23, Modena, Mucchi, 1941, n 33; no es el único caso: véase por ejemplo los números 10, 13 y 78.

46. Véanse algunas ballette del cancionero de Oxford, publicado por Georg Steffens, "Die altfranzösische Liederhandschrift der Bodleiana in Oxford, Douce 308", Archiv für das Studium der neuren Sprachen und Litteraturen, 97, 1896, pp. 283-308, 98, 1897, pp. 59-80 y 343-382, 99, 1898, pp. 77-100 y 339-388 y 104, 1900, pp. 331-354, especialmente vol. 99 , pp. $339-388, n^{\circ} 94,152$ y 181 .

47. Es fácil seguir las ocurrencias de esta modalidad de inserción para la literatura italiana gracias a Linda Pagnotta, Repertorio metrico della ballata italiana. Secoli XIII e XIV, Milano-Napoli, Riccardo Ricciardi, 1995, que confeccionó dos listas de "Ballate a coblas capdenals (collegamento regolare)" y "Ballate a coblas capdenals (collegamento irregolare)"; sin embargo, al no tener en cuenta el tipo de fenómenos que ahora estudiamos, la regularidad o irregularidad no puede considerarse en sentido estricto; en general, casi todos los tipos enumerados (interesan los que tipifica como R-I) responden al tipo de repetición aproximativa de una o varias palabras del incipit del estribillo en el primer verso de la primera estrofa. 
La inserción del estribillo en la estrofa tiene pues un alcance mucho más amplio de lo que la bibliografía sobre el tema suele abarcar, y resulta mucho más compleja de lo que permite suponer el análisis de los dos géneros consolidados en las líricas provenzal y francesa; por otro lado, permite reconstruir lo que pudo haber sido el origen de estas formas primitivas, tal como habitualmente las conocemos: de un magma de repeticiones variadísimas, presentes en todo el ámbito de la Romania (y, seguramente, también fuera de ella) los poetas acogieron una variedad, la codificaron y la canonizaron en sendas formas fijas, el rondeau y la ballata. Pero éstas, en la vida real, hubieron de convivir con las mismas realizaciones amorfas que las habían originado y con hibridaciones más o menos influidas por las formas ya fijadas; un fenómeno que se observa muy bien en la lírica galaico-portuguesa y cuya casuística no es este el lugar de discutir ${ }^{48}$.

Así llegamos, por fin, a la tercera forma y la más difundida, la estrofa con vuelta, objeto de numerosos estudios que, a pesar de su indudable calidad y del nivel de sus autores, no siempre han aclarado el problema, que reviste numerosos y espinosos aspectos. En primer lugar, su aparición simultánea en las líricas latina ${ }^{49}$ y romances y en la árabe clásica y vulgar (y aquí con estimable anterioridad cronológica) lo han situado incómodamente en el núcleo de la problemática de los orígenes; en segundo lugar, habiéndose orientado la mayor parte de la bibliografía aparecida durante los siglos XIX y XX hacia la resolución de este problema, se ha tendido más a orientaciones teóricas (cuando no a una mera toma de partido) que a estudios descriptivos, con la desorientación consiguiente y, a veces, una invencible saturación. Sus distintas variedades estróficas, que encerramos habitualmente bajo diversas denominaciones, acabaron integrándose en la lírica escrita a través de determinados géneros de forma fija, que devinieron centrales en la poética de la Baja Edad Media: zéjel, moaxaja, dansa, ballata, ballette, virelai, rondeau, villancico, etc. Entre los romanistas y los musicólogos, suele triunfar el término virelai, que aquí usaremos también como marbete genérico.

Hasta muy avanzado el siglo XX, la anterioridad de los textos arábigos hacía que los romanistas tendieran hacia dos hipótesis: el origen árabe ${ }^{50} \mathrm{o}$ la poligénesis para el virelai ${ }^{51}$, mientras algunos arabistas, a la zaga de Emilio García Gómez ${ }^{52}$, proponían origen romance ${ }^{53}$, apo-

48. Avancé muchos datos de este tipo en mi "Rondel y refram intercalar en la lírica gallego-portuguesa". arriba citado.

344.

49. Para este aspecto véase el estado de la cuestión de Anglès, La música a Catalunya fins al segle XIII, pp. 342-

50. Avanzado por primera vez por los arabistas el conde de Schack y Julián Ribera, su mayor abanderado fue Ramón Menéndez Pidal, cuyas teorías pueden verse principalmente en los trabajos que fueron recientemente reunidos en el volumen Islam y cristiandad. España entre las dos culturas, ed. Álvaro Galmés de Fuentes, Málaga, Universidad, 2001, Analecta Malacitana, Anejos, 33, sección IV-C, pp. 349-606; aunque en la segunda mitad del siglo XX parece haber decaído, véase aún el respeto que estas teorías merecen a un romanista de la talla de Aurelio Roncaglia, "'Laizat estar lo gazel”, $C u l$ tura Neolatina, 9, 1949, pp. 67-99.

51. Cuyo más acérrimo defensor ha sido quizá Pierre Le Gentil, Le virelai et le villancico. Le problème des origines arabes, Collection Portugaise, IX, París, Institut Français au Portugal-Les Belles Letres, 1954.

52. Véase muy en particular su "La lírica hispanoárabe y la aparición de la lírica románica", en Al-Andalus, 21, 1956, pp. 303-338 y "Métrica de la moaxaja y métrica española. Aplicación de un nuevo método de medición completa al 'Gais' de Ben al-Hatib", en Al-Andalus, 39, 1974, pp. 1-125.

53. Hipótesis a la que me sumé en mi "De zéjeles y dansas: orígenes y formación de la estrofa con vuelta", en Revista de Filología Española, 64, 1984, pp. 239-266. 
yándose en la existencia de la jarcha, estribillo a veces en lengua mozárabe que cerraba la moa$x a j a$. A fines del siglo XX se ha producido una reacción arabizante que tiende a negar la presencia de elementos romances en las formas árabes ${ }^{54}$; por ende, o bien hay que aceptar el origen árabe del conjunto o bien la coincidencia de una misma forma estrófica habría resultado fruto del azar. Creo sin embargo que las hipótesis, para ser aceptadas, no basta que tengan coherencia interna, sino que han de tenerla también con los datos del conjunto de los hechos culturales en que se integran; y en este sentido no puede olvidarse, como hacen estos autores, que el zéjel y la moaxaja no nacen en Persia, ni en Egipto, ni siquiera en Marruecos, sino en Andalucía, donde convivían árabes y mozárabes, ni que este último género se asociaba a un texto poético en lengua vulgar que, a menudo, había sido compuesto en lengua mozárabe, ni que son también muchos los romancismos presentes en los zéjeles de Ibn Quzman. E ignoran otras coincidencias, sobre alguna de las cuales habremos de detenernos. De ahí mis reservas: creo que la explicación, sea cual fuere, ha de abarcar los fenómenos presentes en las líricas arábiga (y, por extensión, hebraica) y las romances. Por otra parte, las formas árabes, aunque integrables y a la postre integradas en la tradición literaria árabe, ofrecen rasgos atípicos en su poética, como la introducción de rimas diversas cuya articulación permite diferenciar una estrofa de otra, o bien una parte de otra en el seno de la estrofa; lo cual las aparta de la forma canónica de la qasida, siempre monorrima. Y es precisamente este aspecto estructural el rasgo común y consubstancial de la composición poética en todas las líricas romances desde sus orígenes.

Pero no es el origen lo que debe preocuparnos, sino su morfología. En su esquema más sencillo, que llamo zejelesco por coincidir con la de este género arábigo-andaluz ${ }^{55}$, consta de un estribillo inicial, seguido de una estrofa trimembre con rimas propias (la mudanza en la terminología castellana), y acaba por una semiestrofa que anticipa parte de las rimas del estribillo, repetido al final (la vuelta, rasgo distintivo de esta forma, sin la que coincidiría con la rotrouenge); como sucede con todas estas formas, las estructuras melódica y estrófica son idénticas:

$$
\begin{aligned}
& \mathrm{A} B / \mathrm{c} \quad \mathrm{c} \quad \mathrm{c} / \mathrm{b} / / \mathrm{A} \mathrm{B} \mathrm{B}^{56} \\
& \alpha \beta_{1} / \gamma_{1} \gamma_{1} \gamma_{2} / \beta_{2} / / \alpha \beta_{1}
\end{aligned}
$$

El modelo es conocido desde muy antiguo, y es muy curioso que una de sus primeras muestras genuinas, si no la primera, sea bilingüe, latina y provenzal ${ }^{57}$ :

54. Véanse a título de muestra (estos temas son objeto de una auténtica especialidad) los sólidos estudios de Otto Zwarties, Love Songs from al-Andalus. History, Structure and Meaning of the 'Kharja', Leiden, Brill, 1997 y Federico Corriente, Poesía dialectal árabe y romance en Alandalús: cejeles y muwassahat, Madrid, Gredos, 1997.

55. En lo esencial sigo aquí las conclusiones de mi trabajo "De zéjeles y dansas: orígenes y formación de la estrofa con vuelta".

56. El esquema corresponde a la Cantiga de Santa María n 96, según Anglès, La música de las Cantigas..., vol. III, págs. 393-394.

57. Cito por la edición que da A. Roncaglia, "'Laisat estar lo gazel”, pp. 69-70. 
[Verbum caro factum est de Virgine Maria]

In hoc anni circulo vita datur seculo, natu nobis parvulo de Virgine Maria
[Verbum caro factum est de Virgine Maria]

Mei amic e mei fiel, laisat estar lo gazel: aprendet u so noel de Virgine Maria

Más adelante volveremos sobre el problema de esta vuelta, que merece atención específica. En adelante, este será el esquema básico del villancico castellano, la ballata italiana y la lauda aunque a veces, sobre todo en las adaptaciones más literaturizadas, el esquema tiende a complicarse. Es posible que la mudanza multiplique el número de versos de cada uno de sus tres miembros; en cuanto a la vuelta, al ampliarse, adquiere rimas diferentes de las del estribillo, que unas veces retoman la última o últimas de la mudanza, a veces introduce rimas distintas a todas las anteriores. Veamos un ejemplo, con su melodía:

$$
\begin{aligned}
& \text { A A B / cdcdcd/e e b//A A B } \\
& \alpha \beta_{1} \gamma / \varepsilon \delta \varepsilon \delta \varepsilon \delta \zeta / \alpha \beta_{2} \gamma / / \alpha \beta_{1} \gamma
\end{aligned}
$$

Los stilnovisti tendieron a complicar todavía más este esquema, llegando a incluir miembros de hasta cuatro rimas distintas en cada una de las tres mudanzas y estribillos de hasta cuatro versos y tres rimas, una peculiaridad que ninguna otra escuela literaria aplicó (por ejemplo: $\mathrm{ABBC} / / \operatorname{defg} \operatorname{defg} / \mathrm{gffc}^{59}$ ). Pero todo ello no son sino ampliaciones del esquema más simple, que tendió a ser utilizado sin tanta complejidad (aunque con las mismas variaciones en la estructura de la mudanza) por los poetas castellanos de la época de los Reyes Católicos, que lo usaron para el villancico cortés ${ }^{60}$.

58. Tomo esta melodía del Laudario de Cortona, $\mathrm{n}^{\circ} 38$, según la edición de $\mathrm{F}$. Liuzzi, La lauda e $i$ primordi della melodia italiana, 2 vol., Roma, 1935, luego estudiados por H. Anglès, La música de las Cantigas..., vol. III, pàgs. $483-513$. Para los esquemas estróficos de las laude ha de acudirse todavía a los repertorios levantados por las ediciones de Liuzzi o de E. Staaff, Le laudario de Pise, Uppsala-Leipzig, 1931. En la última década han proliferado los estudios sobre laudarios; véase por ejemplo Renzo Rabboni, Laudari e canzonieri nella Firenze del '400. Scrittura privata e modelli nel 'Vat. Barb. lat. 3679', Collana del Dipatimento di Italianistica, 8, Bologna, Università, 1991, Roberta Manetti, Laudario di Santa Maria della Scala. Edizione critica a cura di..., Firenze, Accademia della Crusca, 1993 y Gina Scentoni, Laudario orvietano, a cura di, prefazione di Maurizio Perugi, Quaderni del Centro per il Collegamento degli Studi Medievali e Umanistici nell'Umbria, 33, Spoleto, Centro Italiano di Studi sull'Alto Medioevo, 1994.

59. Se trata de una ballata de Lapo Gianni, "Eo sono Amor, che per mia libertate", que cito según Gianfranco Contini, Poeti del Duecento, vol. II, Milano-Napoli, Riccardo Riciardi, 1960, p. 571. Para los esquemas estróficos de la ballata véase Pagnotta, Repertorio metrico..., arriba citado.

60. Para las formas estróficas de este género véase Antonio Sánchez Romeralo, Ob. cit., 42-48, así como el estudio específico de de María Morrás, “¿Zéjeles o formas zejelescas? Observaciones para el estudio de un problema de historia literaria”, La Corónica, 17, Fall, 1988, pp. 52-75 y "Fortuna de las formas zejelescas en la poesía castellana", en Les formes fixes dans la poésie du Moyen Âge roman (1000-1500), Atalaya, 8, 1997, pp. 113-134 e Isabella Tomassetti, Il villancico cortese: studio tematico-formale di un genere, Roma, Università degli Studi "La Sapienza", 2001, tesis de doctorado en vías de publicación por el Centro Juan Alfonso de Baena. Pueden rastrearse también en el Repertorio métrico de la poesía cancioneril del siglo XV. Basado en los textos del Cancionero del siglo XV de Brian Dutton, por Ana Mª́mez-Bravo, Alcalá de Henares, Universidad, 1998. 
En francés y occitano, donde se le conoció, como sabemos, como virelai ${ }^{61}$ y dansa ${ }^{62}$ respectivamente, se difundió un modelo alternativo, basado en una mudanza bimembre y una vuelta simétrica al estribillo que podemos representar con dos poemas de idéntica estructura:

$$
\begin{aligned}
& \text { A B A B / c d c d / a b a b } \\
& \alpha \beta_{1} \alpha \beta_{2} / \gamma \delta \gamma \delta / \alpha \beta_{1} \alpha \beta_{2}
\end{aligned}
$$

El esquema sufriría también variaciones y complicaciones; los virelais, sobre todo a partir de Machaut, tienden a aumentar el número de versos, sobre todo en la mudanza, donde alternan los largos y breves. Sin embargo, el número de sus rimas no suele exceder el de dos, que se van repitiendo en versos generalmente sucesivos; y es corriente que la mudanza repita rimas del estribillo, quizá por influjo del rondeau, como puede verse en este esquema del poeta y músico que inspiró toda la poesía francesa bajomedieval:

$$
\begin{aligned}
& \mathrm{AA} B \mathrm{~B} A \mathrm{~A} B / / \mathrm{bb} a \text { bba / aa baa } b / \mathrm{AA} B \mathrm{~B} A \mathrm{~A} B^{64} \\
& \alpha \beta \gamma_{1} \delta \varepsilon \zeta \eta_{2} / / \mathrm{\iota} \lambda \iota \kappa \lambda / \alpha \beta \gamma \delta \varepsilon \zeta \eta / / \alpha \beta \gamma_{1} \delta \varepsilon \zeta \eta_{2}
\end{aligned}
$$

Otro aspecto a considerar es el funcionamiento semántico y formal del estribillo. Ya vimos cómo, de forma semejante al rondeau y la ballata, es corriente que algunos textos, sobre todo los más simples y primitivos, comiencen la glosa (la primera mudanza) repitiendo el incipit del estribillo, aunque no en segunda o tercera posición de la estrofa como aquellos dos géneros, sino en su primer o primeros versos. Carácter totalmente distinto tiene el recurso que la preceptiva provenzal denomina retronx, consistente en cerrar la vuelta con texto del final del estribillo: un o unos versos completos (en cualquier caso, han de ser menos de la mitad de su texto) o, cuanto menos, una o unas palabras en la rima. Este recurso aparece descrito como una variante de la dansa, la dansa retronxada, en las Leys d'amors, preceptiva provenzal del siglo XIV ${ }^{65}$; el ejem-

61. Pueden verse las estructuras estróficas del virelai anterior a Machaut a partir de Ulrich Mölk y Friedrich Wolfzettel, Répertoire métrique de la poésie lyrique française des origines à 1350, München, Wilhelm Fink Verlag, 1972, donde incluye una relación de los esquemas correspondientes a este género en la ficha 6.

62. Para la dansa provenzal del período clásico podemos partir del Répertoire de Istvan Frank, donde levanta una relación en el vol. II, p. 70; la dansa catalano-provenzal y catalana puede extractarse a partir de Jordi Parramon i Blasco, Repertori mètric de la poesia catalana medieval, Barcelona, Curial Edicions Catalanes - Publicacions de l'Abadia de Montserrat, 1993, que contiene una relación de las obras correspondientes a este género en las pp. 269-270. La profesora Gemma Avenoza está preparando un estudio completo de la evolución y características de este género en la tradición occitana y catalana del que ha avanzado una parte en "La dansa. Introduccióón a la tipología de un género románico", II Congreso Internacional sobre el Cancionero de Baena, Baena, 16-20 de abril del 2002, actas en prensa.

63. El esquema es común a dos dansas provenzales, Domna, pois vos ai... y Tant es gaia..., según Anglès, La música a Catalunya fins al segel XIII, pp. 353 y ss, donde transcribe el ms. 844 de la Bibliothèque Nationale de París; los textos fueron publicados por Karl Appel, Provenzalische Inedita aus pariser Handschriften, Leipzig, 1890, pp. 322 y 331 respectivamente.

64. Cito este esquema, procedente del Remède de Fortune, según Poirion, Ob. cit., p. 327.

65. Ed. J. Anglade, vol. II, p. 180. Se refiere también al retronx la Doctrina de compondre dictats, de fines del siglo XIII, cuando dice que "Si vols far dança... potz fer, si·t vols, totes les fins de les cobles en refrayn semblan" (ed. J. H. Marshall, The Razos de Trobar of Raimon Vidal and associated texts, Oxford, Oxford University Press, 1972, lineas 54-55). 
plo trovadoresco más arcaico que conozco procede de la lírica galaico-portuguesa, una composición de Paay Soarez de Taveiros, en la primera mitad del siglo XIII:

Donas, veeredes a prol que lhi ten de lhi saberem ca mi quer gram ben.

Par Deus, donas, ben podedes jurar do meu amigo que mi fez pesar, mais, Deus! e que cuida mi a gaar de lhi saberem ca mi quer gram ben $?^{66}$

Nótese que nos hallamos ante un esquema del tipo AA // bbb / a, donde la vuelta ha sustituido un verso de texto nuevo por el último del estribillo, un fenómeno ya presente en el texto latino-provenzal Verbum caro, antes estudiado. Un problema que quizá carecemos de testimonios para resolver es hasta qué punto, en estos casos, era preceptiva la repetición íntegra del estribillo que, no obstante, está asegurada en algunos manuscritos. El mismo procedimiento podemos localizarlo en canciones tradicionales castellanas de hacia 1500:
Y la mi cinta dorada
¿por qué me la quitó
quien no me la dio?
La mi cinta de oro fino
diómela mi lindo amigo,
tomómela mi marido.
¿Por qué me la quitó
quien no me la dio ${ }^{67}$

Obsérvese el doble juego de repeticiones, primero de entrada, después, el retronx, que convierten este bello poema en un juego de construcción textual muy próximo al rondeau. A veces, por no haber tomado en cuenta las prescripciones de las Leys d'amors ni su aparición en otras escuelas, se ha negado el carácter de zejelescas a estas composiciones, por carecer aparentemente de verso de vuelta ${ }^{68}$.

No es difícil sin embargo trazar el desarrollo de este recurso, conocido por la dansa catalano-provenzal de los siglos XIV y XV, como este curioso espécimen de principios del XIV cuya rúbrica lo identifica como dançia retronxada:

No:m pux d'aymar vos estrayre,

dolça dompnha, tant vos vey

avinent e de bon ayre.

66. Cito según Gema Vallín, Las cantigas de Pay Soarez de Taveirós. Estudio histórico y edición, $\mathrm{n}^{\circ}$ 14, y también en J. J. Nunes, Cantigas d'amigo, $\mathrm{n}^{\circ} 73$.

67. Frenk, Corpus de la antigua lírica popular hispánica, $\mathrm{n}^{\circ} 237$.

68. Margit Frenk, "El zéjel: ¿forma popular castellana?", en Studia Iberica. Festschrift für Hans Flasche, BernMünchen, 1973, pp. 145-158, que cito por sus Estudios sobre lírica antigua, pp. 309-326. 
Ay bels cors clar, netz, ab gay pretz, pus vesets que·us am, con merce non havets? Gentil, bel abril, mays humil e plasen que re, per vos, ni cosis ni frayre non am tant can vos, qu'envey, avinent $e$ de bon ayre ${ }^{69}$

cuyo estribillo, mudanza y vuelta, siguen la estructura ABA // cded / abA. El mismo esquema fue importado por los poetas castellanos del siglo XV, al parecer de la mano del Marqués de Santillana, para implantarlo primero en la canción cortés, después en el villancico ${ }^{70}$.

Sin embargo, el caso más significativo lo encontramos en los zéjeles árabes de As-Sustari, poeta místico granadino de mediados del siglo XIII; ante la dificultad de componer numerosos de los signos usados en la transliteración de la versión árabe, optaré por dar sólo la versión castellana:

Pardiez, pardiez, los hombres desatinaron por amor del Amado;

Dios, Dios está conmigo presente, próximo a mi corazón.

Presume, corazón mío, y goza, pues llegó tu Amado,

disfruta con la mención de tu Señor, sigue la huella,

exulta y vive ufano entre la humanidad.

Dejadme, dejadme hablar del Amado: de mencionarlo me huelgo:

Dios, Dios está conmigo presente, próximo a mi corazón ${ }^{71}$.

El esquema estrófico, según su editor, se ajusta a la fórmula AA // bbb / aA, y no es, ni de lejos, el único caso de este tipo ${ }^{72}$. Creo que este poeta demuestra hasta la saciedad la comunidad de origen (y, quizá, los contactos históricos repetidos) estre las escuelas árabe y romance; de otra manera, resultaría inexplicable, por mera poligénesis, no ya la plena coexistencia de una misma fórmula estrófica, sino la presencia de este recurso, tan preciso, a ambos lados de una frontera lingüística que tiende a juzgarse impenetrable.

69. Cito según la edición Lola Badia, Poesia catalana del S. XIV. Edició i estudi del Cançoneret de Ripoll, Barcelona, Quaderns Crema, 1983, ${ }^{\circ}$ 6. El estudio en vías de publicación de Gemma Avenoza sobre la forma de la dansa arrojará nueva luz sobre el uso de este recurso en la Baja Edad Media.

70. Me ocupé de estos aspectos en mi "La Leonoreta del Amadís", en Actas del I Congreso de la Asociación Hispánica de Literatura Medieval, Barcelona, PPU, 1988, pp. 187-198 y en La canción de amor en el otoño de la Edad Media, Barcelona, PPU, 1989, especialmente en las pp. 51-53, 104-108, 115-122, 137-139, 143-146 y 188-193, aunque ya Pierre Le Gentil, La poésie lyrique espagnole et portugaise à la fin du Moyen Age, vol. II, Rennes, Plihon, 1953, pp. 270-275 había llamado la atención sobre su presencia en la dansa y la poesía castellana atribuyéndola al influjo del virelai, donde paradójicamente nunca aparecen.

71. Cito según F[ederico] Corriente, Poesía estrófica (cejeles y/o muwa ah t) atribuida al místico granadino AsSustari (siglo XIII d.C.), Madrid, Consejo Superior de Investigaciones Científicas-Instituto de Filología. Dep. de Estudios Árabes, $1988, \mathrm{n}^{\circ} 3$, p. 212; el texto original, en transliteración con caracteres latinos, en la p. 2. Fue ya Le Gentil Le virelai et le villancico, pp. 60-61 quien llamó la atención sobre este fenómeno, que le fue señalado por M. Colin.

72. El autor establece los esquemas estróficos de todas las composiciones en las pp. 14-17; los adapto a las convenciones que sigo en este trabajo. Los versos del estribillo objeto de repetición van en mayúscula. 
El resultado de este sondeo por el desarrollo de las formas simples con estribillo en la lírica románica no puede ser más coherente, ni más rico. En primer lugar, hemos de destacar que su historia puede remontarse más allá de los orígenes de las letras romances; si el primer género consolidado, la hagiografía, no empieza su andadura, lenta y espaciada, hasta el año mil ${ }^{73}$, si el primer trovador, Guilhem de Peitieu, nació en 1071 y la primera gesta, la Chanson de Roland, ha de situarse unos veinte años más tarde, los rondeaux franco-latinos de Hilario el Inglés pueden datar de la primera mitad del siglo XII, el Sponsus resulta un tanto anterior al año 1100, y el Alba de Fleury permite remontar la rotrouenge hasta fechas tan antiguas como el mítico año 1000; nada comparable a la invención de la poesía estrófica árabe, rama semítica del virelai, en la centuria anterior ${ }^{74}$. En segundo lugar, desde sus documentaciones más antiguas, los tres tipos se manifiestan plenamente formados, diferenciados por todos sus rasgos esenciales.

Si los estudios sobre el origen de la lírica romance tendían remontar todos los géneros considerados primitivos a una edad adánica, en la que, desde un germen determinado (las fiestas de mayo, ciertos géneros paralitúrgicos, el zéjel árabe), se fueron diversificando e individualizando las formas conocidas, este repaso manifiesta, muy al contrario, que desde el mismo momento de su emergencia plena a la escritura, la lírica primitiva en lengua vulgar conocía ya diversas modalidades formales plenamente desarrolladas, asociadas a esquemas musicales asimilables a su estructura estrófica y seguramente arraigadas en la tradición oral de toda la Romania, de donde habrían ido emergiendo hasta su paso, quizá accidental y acaso accidentado, a las primeras manifestaciones escritas.

Por último, en todas estas formas el estribillo ocupa un papel central y esencial. No sólo constituye el núcleo de donde parte la forma y el contenido del poema, sino que éste y su estribillo resultan inseparables sin la destrucción del conjunto, a diferencia de la lírica cortés, donde estribillo y estrofa pueden ser meras entidades yuxtapuestas; es lo que sucede, por ejemplo, en la llamada chanson avec des refrains, tan frecuente en francés durante el siglo XIII, donde a una estructura fija de la estrofa se van añadiendo estribillos de contenidos y formas variados ${ }^{75}$.

Muchos son los problemas pendientes en el estudio de los estribillos. Habría que dilucidar por ejemplo su origen y formación: ¿fueron siempre estribillos, se desgajaron en algún momento del cuerpo de una estrofa? ¿Hasta dónde podemos asegurar que proceden de la imitación de textos escritos, y hasta qué punto es posible proponer una transmisión oral? Demasiados problemas todavía para un elemento tan esencial de la tradición lírica romance; con todo, a la luz de los datos expuestos, creo que las formas con estribillo han de ser consideradas como las más antiguas y simples entre los géneros poéticos conocidos en lengua vulgar.

73. C. Segre hizo un uso magistral de la secuencia cronológica de las vidas de santos, en relación con la más tardía epopeya, en su "Problemi di tradizioni di testi romanzi: dai poemetti agiografici alle 'chansons de geste"”, primero en Concetto, storia, miti e immagini del Medio Evo, a cura di V. Branca, Firenze, Sansoni, 1973, pp. 339-351, que cito por su reimpresión, con leve cambio de título, en su La tradizione della 'Chanson de Roland', Milano-Napoli, Riccardo Ricciardi, 1974, pp. 80-93.

74. Los datos fundamentales de esta historia pueden seguirse a través de F. Corriente, Poesía dialectal árabe y romance en Alandalús, pp. 70-89, apasionado arabizante y hostil a toda vinculación de la tradición árabe y románica.

75. Véase la lista en Mölk y Wolfzettel, Ob. cit., ficha 55; para el funcionamiento del refrain el los trouvères, véase el estudio de Eglal Doss-Quinby, Les refrains chez les trouvères du XII" siècle au début du XIVe, New York, Peter Lang, 1984. 